\author{
Journal of International Business Research and \\ Marketing \\ Volume 6, Issue 4, 2021 \\ journal homepage: www.researchleap.com
}

\title{
The Role of ICT on Cultural Heritage Tourism: a Case Study
}

\author{
Abe Akihiro \\ Iwate Prefectural University, Faculty of Software \& Information Science, Japan
}

\begin{tabular}{|l|l|}
\hline & ABSTRACT \\
\hline $\begin{array}{l}\text { 2016 Research Leap/Inovatus Services Ltd. } \\
\text { All rights reserved. }\end{array}$ & $\begin{array}{l}\text { The purpose of this study is to discuss the role of ICT in cultural heritage tourism through a } \\
\text { case study of the Hiraizumi world heritage site in Japan that was registered in 2011. As it } \\
\text { promotes tourism through the world heritage registration, Hiraizumi is operating on the major } \\
\text { premise that it will safeguard its cultural heritage while also placing importance on developing } \\
\text { URL: } \text { http://dx.doi.org/10.18775/jibrm.1849- } \\
\text { 8558.2015.64.3004 }\end{array}$ \\
$\begin{array}{l}\text { Systems for accepting a diverse range of tourists using the universal design perspective. When } \\
\text { doing so there are limits to facility refurbishment and infrastructure development so the town } \\
\text { focused its attention on support for information aspects, or in other words support using ICT. } \\
\text { Going forward as individual travel becomes more mainstream the ways in which new value is } \\
\text { information, Tourism promotion and cultural } \\
\text { property protection, World Heritage }\end{array}$ & $\begin{array}{l}\text { created in Hiraizumi tourism are likely to include (1) transmission of the value of the cultural } \\
\text { heritage in collaboration with researchers and (2) development of tourist areas in which } \\
\text { excursions on foot are possible. We discuss the possibilities for utilization of ICT in these } \\
\text { measures and the utility of the participatory design approach. }\end{array}$ \\
\hline
\end{tabular}

\section{Introduction}

In June 2011 the cultural heritage of Hiraizumi was registered as UNESCO world cultural heritage under the name "Hiraizumi-Temples, Gardens and Archaeological Sites Representing the Buddhist Pure Land," realizing an ardent wish of the town. The town had fought back after the nomination had been rejected in 2008 and overcame many obstacles to achieve registration including reducing the number of sites covered by the nomination from the initial nine sites to five sites (Chuson-ji, Motsu-ji, Kanjizaio-in Ato, Muryoko-in Ato, and Mt.Kinkeisan), so the excitement of the local people was all the greater when the registration was finally achieved. For Iwate Prefecture and all of the northeastern Japan suffered from the Tohoku earthquake and tsunami of 11 March 2011, the registration proved to be a ray of hope. Through registration as a World Heritage Site, various plans and operations were initiated to promote and vitalize tourism in Iwate prefecture and the Tohoku region centered around Hiraizumi. On the other hand, the gap between the inland areas of the relatively unaffected prefectures and the seriously damaged coastal areas, which still have not restored their facilities, continues unabated.

Hiraizumi is a well-preserved grouping of a wide variety of temples and gardens built on the basis of the Pure Land thought of Buddhism (Figure 1). The temples and gardens attempted to create an ideal world in our world, and developed in a uniquely Japanese way while receiving foreign influences. The expression of the ideal world at Hiraizumi is seen as being without parallel anywhere else. In order to register a site as a World Heritage site, it is necessary for the resource to have a "marked and universal value." In order to prove this, it is necessary to show that the site corresponds to at least one evaluation standard among six stipulated by the Word Heritage Committee, is authentic and complete, and possesses an effective conservation administration system. Hiraizumi was evaluated in categories "interchange" and "association" among the six evaluation standards: masterpiece, interchange, testimony, example, landuse and association.

Together with the registration of the world heritage, the tourist guide system built through joint research by the town of Hiraizumi and the laboratory of the author commenced operation. Our laboratory is working on education and research related to a practical information system with the issue of community informatization as our theme, and this system was also created in response to a request from the town, which is facing the issue of how to handle the increase in tourists after world heritage registration. In this paper we discuss the role of ICT in cultural heritage tourism based on the case of the initiative undertaken by the author in Hiraizumi. 


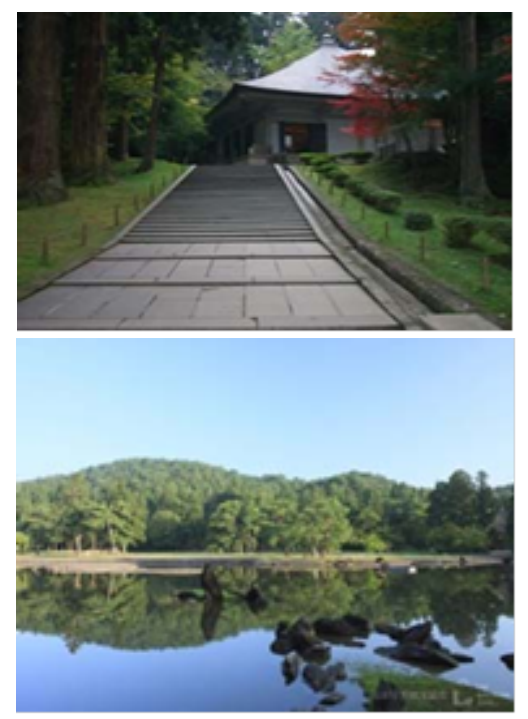

Figure 1: Hiraizumi world heritage site

\section{World Heritage Registration and Tourism Promotion}

\subsection{Tourist Increases and Universal Design}

In tourist areas there is growing emphasis on the universal design (UD) or design-for-all approach which takes into account different kinds of people such as elderly people, people with disabilities, and foreigners. The factors behind this include the recognition both internationally and domestically of travel as a right belonging to all people, the aging society, the diversification of tourists and more small group tourism, and efforts to attract foreign tourists. Through laws and regulations concerning UD, the mobility environment for the handicapped and elderly was improved. Not only have areas that are regularly utilized with a high frequency been improved, but also non-everyday environments such as tour destinations are also being upgraded. However, tourism includes a wide variety of factors, and by linking them organically, tours with a high degree of satisfaction can be achieved. In UD, when advances in upgrading and improvements are made, increased demands appear. It is necessary to make improvements as they become possible with the goal of providing tourists with an even higher degree of satisfaction.

In the period from 2005 to 2007 the Hiraizumi region established the UD Tourist Areas Promotion Council and took measures for the UD Promotion Program in preparation for the 2008 world heritage registration. Handling the increase in tourists from both Japan and overseas emerged as one of the major issues but it became apparent that introducing UD would be difficult using only measures such as putting up signs in the locality, facility development, and the provision of guide staff, as a result of problems such as maintenance of the landscape and cost increases. Furthermore, with approaches centered on the distribution of print media, the trash problem is a concern. Therefore, expectations grew regarding introducing supplementary UD in which information is provided using the mobile phones of the tourists themselves, and introduction of a tourist guide system based on UD was incorporated in the plans (Abe, Maita, Ooshida and Kano, 2007)

\subsection{Environmental Changes in the Tourism Industry}

According to a report by a private market research company familiar with the conditions in the tourism industry, since the commencement of their survey in 2005 the market for travel with accommodation has been continuously declining in Japan. Over half of the market is taken up by middle aged and elderly people over fifty, while at the same time the decline in young tourists exceeds the decline in their population. Lack of interest in tourism is serious. The percent of package tours in 2009 was $12.5 \%$, but in 2011 it had declined to $11 \%$. The percent of individual tours is clearly rising. Furthermore, tourists do not come only to enjoy the famous world heritage sites; increasingly they seek tourism value for their total space and time, including their travel before and after touring the world heritage sites, meals, accommodation, and hands-on experiences.

Even Hiraizumi, which has achieved world heritage registration, must appropriately analyze and take measures to respond to these transformations in the tourism market of a "shift to individual tour" and a "shift from consumption of things to consumption of time." It is said that generally the increase in tourists due to the effect of world heritage registration levels out after a few years, but the tourism promotion implemented by local governments to date has mainly been confined to package travel measures, and has not constituted an approach to the individual tour market which accounts for $90 \%$ of tourism.

\subsection{Current Status of ICT Utilization in Hiraizumi Tourism}

Firstly, we provide a commentary on the basic matters related to tourism information. The grouping axes of tourism information are (i) tourist behavior (beforehand, locally, afterwards), (ii) temporal aspects (static and dynamic), and (iii) spatial aspects (surfaces, lines, points), and the relationships between these forms of tourism information transmission and the media can be summarized as in Fig. 2 . Next, we mentioned that it is easy to understand tour activity through a consumer activity model. Tourists pay attention to a particular tour destination and tour product. When they are interested they search for the details, make comparisons with similar destinations and products, and examine where they want to go. When they have decided that they want to go on a tour, they make plans, travel to the site, and enjoy it. After the tour they share their observations and experiences with family and friends, and disseminate them. This model is called AISCEAS after the initial letters of each of the activities (attention, interest, search, comparison, examination, action and share). 


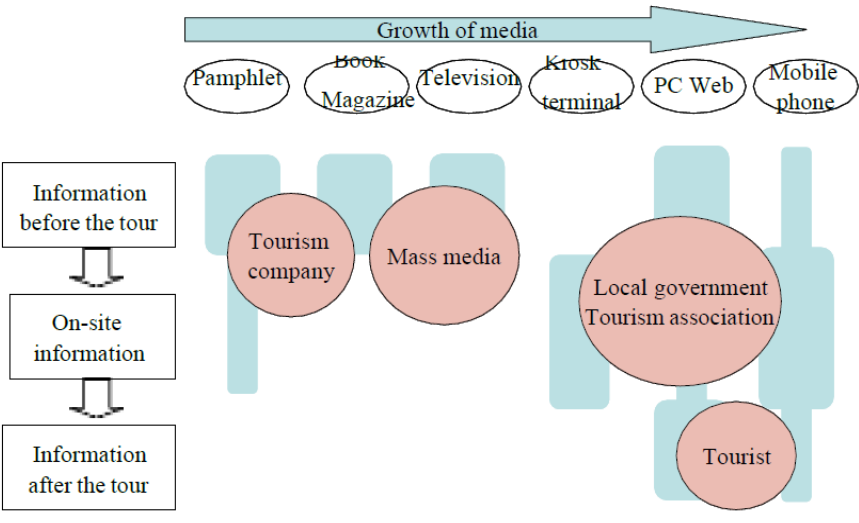

Figure 2: Tourism information transmission and media

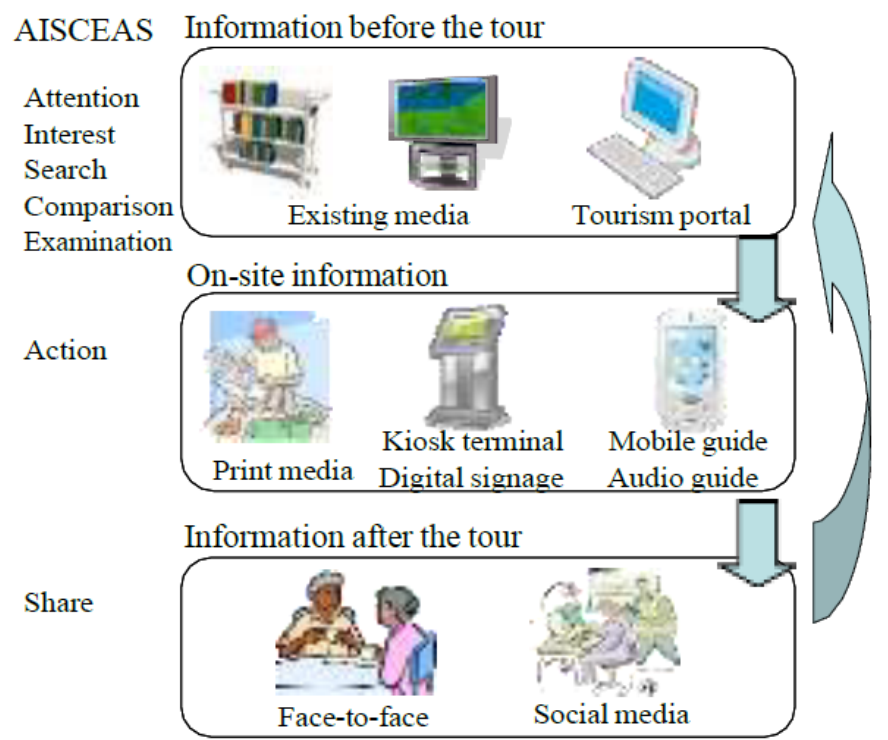

Figure 3: ICT utilization in Hiraizumi tourism

Following that, we summarized the ICT utilization situation regarding Hiraizumi tourism based on AISCEAS model (Fig.3). Information before the tour is provided by multiple government and tourism association portals, and on-site information is focused on print media complemented in part by the mobile/audio guide and digital signage. Information after the tour depends entirely on user promotion, and at present there is no organized capability making use of social media.

The distinctive feature of the tourist guide system is that it takes into consideration individual differences in tourism needs (differences in the pace of tourism, information acquisition methods, and the necessary information) based on the UD concept so it can meet the needs of diverse users with one mobile phone (Fig.4) (Ichikawa, Fukuoka, Ooshida, Kano and Abe, 2012). Information distribution at tourism spots combines the push type and the pull type. The context help handles the physical characteristics and position of the user, but the physical characteristics use a selection format from the screen, and the position information is compatible with GPS and QR codes.
Functions include commentary, route guidance and quizzes, and these are controlled by the UD support function, so information is provided taking into consideration user characteristics, for example only audio guidance is given to people with visual impairment. The audio guidance uses speech synthesis, and in the smart phone version the users themselves can change the speaker and change the speed of the audio.

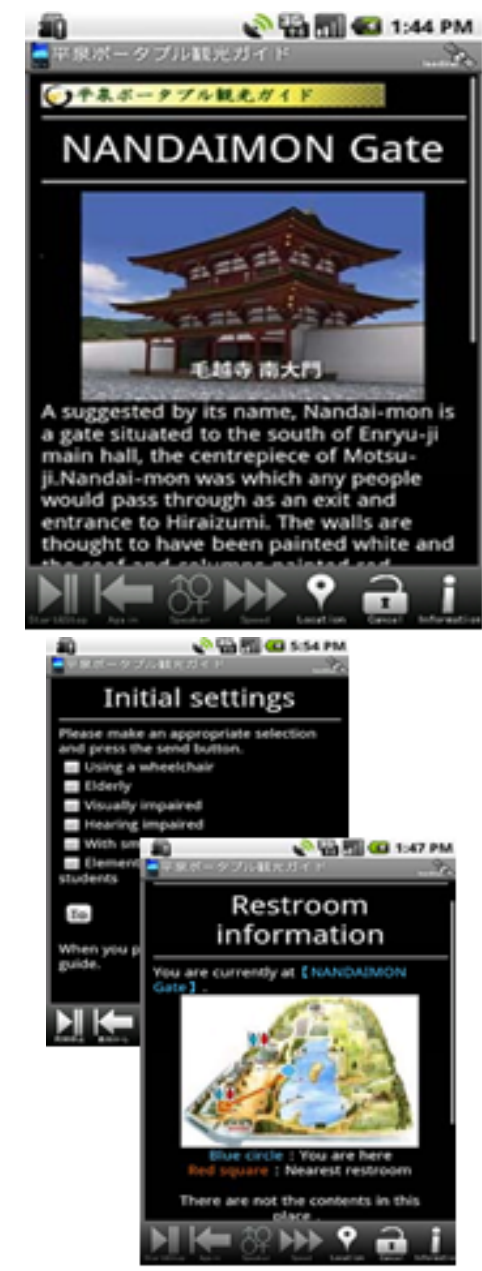

Figure 4: UD mobile guide system



Figure 5: Human-centred design processes 


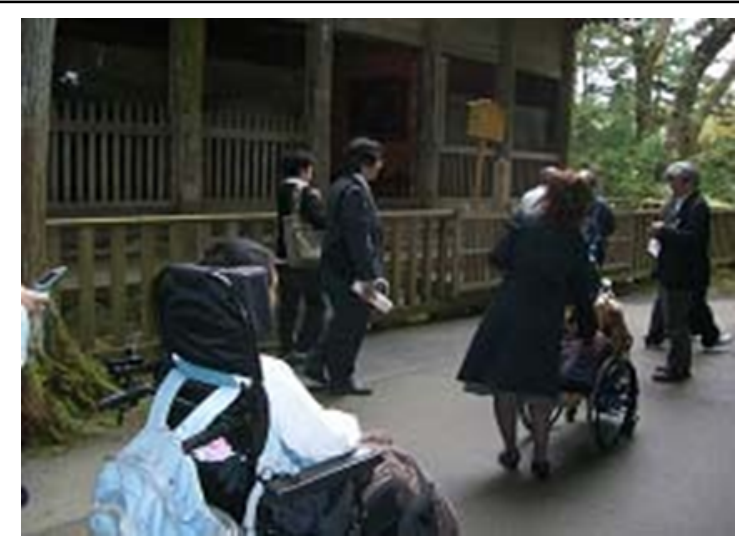

Figure 6: Tourism workshop for participatory design

UD focuses on the spiral up approach in which improvements are made repeatedly based on user participation to make the service better and to disseminate it more widely. The distinctive feature of the planning, development and introduction of this system is that the participatory design approach was adopted in accordance with standard ISO 9241210 (Figure 5). The designers carried out workshop many times involving walking around the tourism facilities and travel routes together with tourism monitors and local residents, and reflected the results in the system design (Figure 6).

\section{New Tourism Value Creation and the Role of ICT}

Due to the widespread use of social media and smart phones tourism promotion using ICT will probably become a more realistic approach going forward, so based on this perception we discuss the creation of new value and the role of ICT in Hiraizumi tourism.

\subsection{Visualization of Heritage Value through E-Heritage Utilization}

Most of the cultural heritage of Hiraizumi has been lost. Hiraizumi's value will not be experienced by simply examining the extant remains. Their recreation and visualization through extended and composite reality technology is anticipated, not only in the academic study of cultural properties, but also in promoting tourism. The strongest demand is for reconstruction and visualization of archaeological sites using augmented reality/mixed reality (AR/MR) technologies. Researchers and technicians tend to focus on the pursuit of reality and historical accuracy but when using these technologies for tourism the care should be taken over the cost-effectiveness of system operation and content copyrights in particular.

If through collaboration between portal sites, the guide system and e-Heritage tourists are able to easily utilize the findings of humanities researchers as knowledge to enable them to decipher the value of the cultural heritage, then surely tourist satisfaction will increase. For example, most people do not know that "the ponds at temples in southeast Asia and India are all square, but the naturally-shaped pond such as at Motsuji temple were conceived of by the Japanese as representing the Pure Land, and the furthest limit of that evolution was achieved at Hiraizumi." There should be more dissemination of prior inductive information, not only on-site information.

\subsection{Information Support for Encouraging Local Stays and Excursions}

At Hiraizumi up to now, tourists viewed Chuson-ji and Motsu-ji at a quick pace and passed on. I hope for an increase in repeat visits by having tourists stay over in the town with accommodations combined with a soothing experiential program to directly experience the Pure land through such means as preaching by the abbot of the temple. For that purpose, efforts to support time consumption locally by assembling landing-led local information while considering a media mix of existing media and ICT media, and transmitting the information meticulously will be necessary.

For example, it would be useful to present information for enjoying the landscape while walking around the cultural heritage spots to the tourists above each spot and the travel routes using smart phones and other devices. It may be a good idea to make an appeal to the handicapped and the elderly as an easily accessible tour destination focusing on the excellent commonality between Pure Land thought and universal design. In that case, by publishing local UD information beforehand regarding the accessibility of various places to wheelchairs or the availability of care giving facilities, it will be easy to match tourists with the local places. In addition, the inclusion of a function supporting the creation of an excursion schedule gives the traveler additional peace of mind on their journey.

\subsection{Big Data Marketing for Individual Tour}

In order to tie in with an expansion in the individual tour market through involvement with the preceding local stays and excursions, it is important to reevaluate local resources and features, and link with the activities of local residents. When so doing, it is critical that such local circumstances as trends in tourists using accommodations survey data on tour marketing, data on accommodations used according to areas from accommodation reservation sites, and so on be correctly grasped as data, analyzed, and utilized in making policies for promoting tourism. Further, as a new possibility in utilizing data, the approach of grasping general tour excursion trends and information access trends from data utilization trends in tourist guide systems using mobile phones, and linking that to environmental maintenance of tour sites to be enjoyed by walking, is very interesting from the point of view of community development.

\section{Conclusion}

In this paper we discussed the role of ICT in world heritage tourism through a case study of the Hiraizumi world heritage 
sites. As it promotes tourism through the world heritage registration, Hiraizumi is operating on the major premise that it will safeguard its tangible and intangible cultural heritage while also placing importance on developing systems for accepting a diverse range of tourists using the universal design perspective. For realizing this objective there is a limit to the hardware approach so the town focused its attention on support for information aspects, or in other words support using ICT. When examining the current status of ICT utilization in Hiraizumi tourism and the approach that would be best going forward we analyzed tourist behavior based on the AISCEAS model, a consumer behavior model. Moreover, going forward as individual travel becomes more mainstream the ways in which new value is created in Hiraizumi tourism are likely to include (1) transmission of the value of the cultural heritage in collaboration with humanities researchers and (2) development of tourist areas in which excursions on foot are possible and information transmission, etc., and we discussed the possibilities for utilization of ICT in these measures and the utility of the participatory design approach.

There is no shortcut to realizing these outcomes, and no change to the town's united efforts for continuous community development activities and tourism promotion, just as in the past. In future research we plan to further deepen our discussion about development of systems for accepting tourists and the best approach to information transmission, through analyses of the tourist excursion data of Hiraizumi.

\section{Literature}

- Abe, A., Maita, N., Ooshida, Y. and Kano, T. (2007). Proposal for a System Based on the Universal Design Approach for Providing Tourism Information by Linking RFID and GIS. In Proceedings of 15th International Conference on Information Systems Development (pp. 247-258). Heidelberg: Springer. CrossRef

- Hiraizumi Tourism Association. World Heritage Hiraizumi.

- Ichikawa, H., Fukuoka, H., Ooshida, Y., Kano, T. and Abe, A. (2012). Development and Evaluation of Universal Design Push-type Audio Guidance with Mobile Phone. Journal of Information Processing.

- ISO 9241-210: (2010). Human-Centred Design for Interactive Systems.

- Iwate Lifelong Learning and Culture Divisio. (2005). The Cultural Heritage of Hiraizumi.

- $\quad$ NC State University. (2010). Center for Universal Design.

- Working tourist destinations. Sourcebook for providing effective tourism information. 